\title{
INCIDENCE OF MILK FEVER AND DESCRIPTION OF APPLIED CONTROL STRATEGIES FOR PREVENTING MILK FEVER/SUBCLINICAL HYPOCALCAEMIA IN LARGE DAIRY HERDS
}

\author{
Jens Hindhede, Anne Kudahl, Jan Tind Sørensen and Betina Knudsen
}

Danish Institute of Agricultural Sciences, Research Centre Foulum. DK-8830 Tjele.

Farmer's choice of feasible strategies for preventing milk fever/subclinical hypocalcaemia amongst several options is motivated and influenced by many factors. When developing strategies for milk fever control in modern dairy herds it is relevant to know what strategies are currently preferred in the herds; but this knowledge is scarce.

During the year 1998/99 a cohort study was performed among a selected group of 38 modern Danish dairy herds on the farmers use of relevant and feasible strategies for preventing milk fever. The requirements to be met by the farms were, that a. The cows should be stalled in loose housing systems $b$. The herd size should be at least 100 dairy cows and c. The farmer should be member of the National Danish Milk Recording Scheme. In addition to this some variation between farms were wanted concerning breed, milk yield per cow, housing, feeding etc. A technician from DIAS visited each farm four times during 1.5 year for data collection: recordings and interviews. The farmer continuously recorded all cases where he observed clear milk fever symptoms and subsequently treated by himself.

The herds in the survey were relatively large ( $>120$ dairy cows) and most practised TMR and group feeding. Dry cows were grouped separately in all 38 herds. The average milk fever incidence for all parities in all 38 herds was 5.3\% (0 - 21\%). The incidence was lowest for cows in first and second parity, but increased progressively with higher parity, thus $17.0 \%$ for cows in 4th or later lactation. There was a large variation in incidences between herds also in same parity, thus from 0 to $3 \%$ in first parity, 0 to $13 \%$ in second parity and 0 to $47 \%$ for cows in 4 th or later lactation.

Options for control of milk fever/subclinical hypocalcaemia were used systematically in 32 of the 38 herds. The proportion of herds using various options was following:

1. Low Calcium content in rations for dry cows $21 \%$

2. Low $\mathrm{Ca} / \mathrm{P}$-ratio in rations for dry cows $\quad 8 \%$

3. Oral calcium drenching around calving $\quad 71 \%$

All other methods were practised very seldom, thus less than in $3 \%$ of the herds. The option Oral calcium drenching around calving was distributed as a main principle in 71 per cent of the herds and typically used after calving and 1 - 2 times per case. Most herds practised treating cows around 3rd or later calving. Special attention for cows with very high condition score is distributed in most herds. The option Low Calcium content in rations for dry cows was often practised, it is however doubtful that the Calcium level was below $20 \mathrm{~g}$ per cow per day, which is required if the option should be effective. The use of Low DCAD in rations for dry cows is very limited, considering the well-documented effect of the option. In many herds, more than one option was used. 